\title{
Orthorexia Nervosa and its association with obsessive-compulsive disorder symptoms: initial cross-cultural comparison between Polish and Italian university students
}

\author{
Anna Brytek-Matera ${ }^{1}$ (D) . Susanna Pardini ${ }^{2} \cdot$ Justyna Modrzejewska $^{3} \cdot$ Adriana Modrzejewska $^{4} \cdot$ Paulina Szymańska $^{1}$. \\ Kamila Czepczor-Bernat ${ }^{1} \cdot$ Caterina Novara $^{2}$
}

Received: 16 February 2021 / Accepted: 27 May 2021 / Published online: 2 June 2021

(c) The Author(s) 2021

\begin{abstract}
There is limited evidence of a link between Orthorexia Nervosa (ON) and Obsessive-Compulsive Disorder (OCD), and no definitive conclusions can be drawn. The interplay between socio-cultural context and ON has been poorly investigated as well. Therefore, the objectives of the present study were: (1) to investigate the differences in ON and OCD symptoms and (2) to assess the relationship between ON and OCD symptoms among university students. Six hundred and sixty-six university students participated in the present study: 286 from Poland and 320 from Italy. No age, gender and marital status differences were identified between two samples of university students. However, on average, Polish university students had a higher Body Mass Index than Italian ones. Our findings showed that Polish students present more problems related to obsessive symptomatology, core beliefs of OCD, perfectionism traits, and a major ON symptomatology than Italian ones. Also, Polish students with a higher level of ON exhibited higher levels of OCD symptoms and parental expectations/parental criticism. While Italian students with a higher level of ON showed higher levels of perfectionism features (organization and concern over mistakes). In general, correlations were low as confirmation of partial independence ON from OCD symptoms and core beliefs of OCD in both Polish and Italian university students. The present results highlight a need for further investigation of the correlates of ON across different cultural groups. Future research may screen individuals with ON to determine the comorbidity between ON and OCD symptomology to facilitate appropriate treatment choices.

Level of evidence Level V, Opinions of respected authorities, based on descriptive studies, narrative reviews, clinical experience, or reports of expert committees.
\end{abstract}

Keywords Orthorexia Nervosa $\cdot$ Obsessive-Compulsive Disorder $\cdot$ Obsessive Belief $\cdot$ Perfectionism $\cdot$ Multi-centered Study

Anna Brytek-Matera

anna.brytek-matera@uwr.edu.pl

1 Institute of Psychology, University of Wroclaw, Dawida 1, 50-527 Wroclaw, Poland

2 Department of General Psychology, University of Padova, Padova, Italy

3 Faculty of Humanities and Social Sciences, University of Bielsko-Biała, Bielsko-Biała, Poland

4 Department of Psychology, Katowice Business University, Katowice, Poland

\section{Introduction}

Healthy eating and healthy lifestyles are deemed to be desirable in Western societies [1,2], with an increasing emphasis on eating good quality or "clean" foods [3]. For some individuals, the pursuit of an "extreme dietary purity" may become obsessive and lead to orthorexic behaviors [4]. Orthorexia Nervosa has been defined in the literature as obsession or fixation or concern/preoccupation [5] with healthy food consumption and disturbing thoughts, excessive worrying, and rigid, compulsive eating behaviors regarding healthy dietary intake, e.g., avoidance of foods considered "unhealthy" or "unclean" [6]. In the light of ON literature, the use of terms concern/preoccupation, obsession, and fixation seems to be complementary since they deal with 
different aspects of the same problem: the concern about healthy diet results in the attention captured by food, thus evolving to a persistent and disturbing thought and stereotyped behavior [5].

One of the proposals for diagnostic criteria [7] suggests two critical features of ON: (a) obsessive focus on dietary practices believed to promote optimum well-being through healthy eating with inflexible dietary rules, recurrent and persistent preoccupations related to food, compulsive behaviors, and (b) consequent, clinically significant, impairment, e.g., medical, physical or psychological complications, significant weight loss, malnutrition, extreme emotional distress with feelings of guilt, shame, anxiety, and impairment in critical areas of functioning. Bratman [8], the author who coined the term ON, has revealed orthorexic behavior is only becoming pathological if obsessive thinking, compulsive behavior, self-punishment, and escalating restriction are presented and become central drivers of life while impeding other important areas take place.

It is still debatable whether ON should formally be recognized as a distinct and separate psychiatric diagnosis: an eating disorder-an antecedent of anorexia nervosa or a way to maintain $\mathrm{AN}$ or a consequence of $\mathrm{AN}$, a form of the obsessive-compulsive disorder (OCD), or assimilated into the spectrum of an already established psychiatric diagnosis [9-12] or merely a new lifestyle phenomenon, a culturally influenced attitude, rather than a disease [8, 13]. It is worth adding that anecdotal reports of consequences of ON, e.g., fatigue and emotional instability, social isolation, reduced quality of life and physical, malnutrition, and weight loss, follow current concepts of mental disorders [14].

\section{Orthorexia Nervosa and obsessive-compulsive disorder: comparison}

Based on the pattern of excessive preoccupation with healthy eating coexistent with features of obsessive-compulsive personality, diagnosis of ON was first proposed in 2004 by Donini et al. [15]. Asil and Sürücüoğlu [16] found that dietitians with ORTO-15 scores less than 40 points showed higher OCD symptoms. Similar results were obtained by Arusoğlu et al. [17], showing that individuals with higher OCD symptoms had greater ON tendencies (Table 1).

On the other hand, some studies have shown that ON prevalence rates among OCD patients are low [18]. Nevertheless, there is initial evidence that $\mathrm{ON}$ and OCD exhibit similar behavioral and thinking patterns (e.g., [5, 9, 11, 19]. Analysis of $\mathrm{ON}$ reveals several overlapping characteristics with OCD (see Fig. 1).
Table 1 Cronbach's alpha related to each subscale used in the present study

\begin{tabular}{|c|c|c|}
\hline \multirow[t]{2}{*}{ EHQ_Total score } & Polish sample & 0.92 \\
\hline & Italian sample & 0.90 \\
\hline \multirow[t]{2}{*}{ EHQ_Knowledge } & Polish sample & 0.83 \\
\hline & Italian sample & 0.83 \\
\hline \multirow[t]{2}{*}{ EHQ_Problems } & Polish sample & 0.88 \\
\hline & Italian sample & 0.85 \\
\hline \multirow[t]{2}{*}{ EHQ_Feelings } & Polish sample & 0.80 \\
\hline & Italian sample & 0.70 \\
\hline \multirow[t]{2}{*}{ OCI_R_Total score } & Polish sample & 0.92 \\
\hline & Italian sample & 0.86 \\
\hline \multirow[t]{2}{*}{ OCI_R_Hoarding } & Polish sample & 0.71 \\
\hline & Italian sample & 0.79 \\
\hline \multirow[t]{2}{*}{ OCI_R_Ordering } & Polish sample & 0.75 \\
\hline & Italian sample & 0.85 \\
\hline \multirow[t]{2}{*}{ OCI_R_Mental Neutralizing } & Polish sample & 0.77 \\
\hline & Italian sample & 0.84 \\
\hline \multirow[t]{2}{*}{ OCI_R_Washing } & Polish sample & 0.71 \\
\hline & Italian sample & 0.75 \\
\hline \multirow[t]{2}{*}{ OCI_R_Obsessing } & Polish sample & 0.84 \\
\hline & Italian sample & 0.89 \\
\hline \multirow[t]{2}{*}{ OCI_R_Checking } & Polish sample & 0.82 \\
\hline & Italian sample & 0.74 \\
\hline \multirow[t]{2}{*}{ OBQ_Total score } & Polish sample & 0.96 \\
\hline & Italian sample & 0.97 \\
\hline \multirow[t]{2}{*}{ OBQ_RT } & Polish sample & 0.91 \\
\hline & Italian sample & 0.89 \\
\hline \multirow[t]{2}{*}{ OBQ_PC } & Polish sample & 0.93 \\
\hline & Italian sample & 0.88 \\
\hline \multirow[t]{2}{*}{ OBQ_ICT } & Polish sample & 0.90 \\
\hline & Italian sample & 0.91 \\
\hline \multirow[t]{2}{*}{ MPS_Total score } & Polish sample & 0.92 \\
\hline & Italian sample & 0.91 \\
\hline \multirow[t]{2}{*}{ MPS_PS } & Polish sample & 0.85 \\
\hline & Italian sample & 0.85 \\
\hline \multirow[t]{2}{*}{ MPS_O } & Polish sample & 0.89 \\
\hline & Italian sample & 0.89 \\
\hline \multirow[t]{2}{*}{ MPS_CMD } & Polish sample & 0.92 \\
\hline & Italian sample & 0.91 \\
\hline \multirow[t]{2}{*}{ MPS_PEPC } & Polish sample & 0.85 \\
\hline & Italian sample & 0.87 \\
\hline
\end{tabular}

\section{Relationship between Orthorexia Nervosa and Obsessive-Compulsive Disorder}

The researchers' point of view on ON's nature turns out to be inconsistent with each other. On the one hand, previous studies have related ON with OCD symptoms in healthy samples [16, 17, 21-23]. Hayes et al. [23] found 


\begin{tabular}{|c|c|}
\hline Orthorexia Nervosa (ON) & Similarities between $\mathrm{ON}$ and $\mathrm{OCD}$ \\
\hline $\begin{array}{l}\text { Healthy eating/food-related symptoms } \\
\text { Intrusive thoughts and repetitive behaviors }\end{array}$ & $\begin{array}{l}\text { The occurrence of persistent thoughts (e.g., } \\
\text { thinking about planning meals), repeating tasks } \\
\text { (e.g., meal preparation with accuracy) }\end{array}$ \\
\hline $\begin{array}{l}\text { thought, behaviors, values, and feelings } \\
\text { that are felt to be acceptable and consistent }\end{array}$ & $\begin{array}{l}\text { Spending time in thoughts and behavior } \\
\text { (selecting and preparing foods) }\end{array}$ \\
\hline with the needs and goals of the individual) & $\begin{array}{l}\text { Social functioning disturbances (e.g., social } \\
\text { isolation) }\end{array}$ \\
\hline & $\begin{array}{l}\text { Lack of perceived quality of life as a } \\
\text { consequence of cognitive intrusions }\end{array}$ \\
\hline & Need to exert control \\
\hline & Cognitive inflexibility \\
\hline & Perfectionism \\
\hline & High anxiety traits (about contaminated food) \\
\hline & Depression \\
\hline & $\begin{array}{l}\text { Feeling guilty (poor adherent to one's own rules } \\
\text { for healthy eating) }\end{array}$ \\
\hline & Concerns about contamination \\
\hline
\end{tabular}

Obsessive-compulsive disorder (OCD)

Non-specific, different types of symptoms

Intrusive obsessive thoughts and repetitive, compulsive behaviors (OCD symptoms) are perceived as ego-dystonic (person's thought, behaviors, values, and feelings that are felt to be unacceptable, dissonant, and inconsistent with the needs and goals of the ego) 
H1: Polish students show more ON behaviors than Italian ones.

$\mathrm{H} 2$ : Students with a high level of ON present high levels of OCD symptoms.

$\mathrm{H} 3$ : $\mathrm{ON}$ is related to OCD symptoms in both Italian and Polish students.

\section{Methods}

\section{Participants and procedure}

The study group consisted of 286 (47.2\%) Polish and 320 (52.8\%) Italian psychology students, respectively, recruited from different universities located in Poland (e.g., Silesian region, Upper Silesia region) and Italy (e.g., northern Italy).

In both countries, recruitment took place during university lessons; specifically, students were given a short general presentation of the project and proposed participating in the research. Individuals had to confirm their participation via email. Through creating an individual account managed and monitored by themselves, the authors sent participants an email with the link to access the protocol through Google Forms. Participants responded to the questionnaires in a single online session; first, they had to sign the informed consent form and fill in the personal datasheet. Then, a battery of counterbalanced self-report questionnaires was administered. A numerical code corresponding accompanied the informed consent form to the one reported on the tests and the personal datasheet. No one of the students was excluded from the research. Protocols with at least $10 \%$ of the answers omitted have been excluded. The questionnaires were administered based on an electronic format by a properly trained psychologist.

A research ethics committee has approved the present study (no. WKEB59/05/2019 in Poland and no. 3067$14 / 06 / 2019$ in Italy). All procedures performed in our study were following the 1964 Helsinki declaration (adopted by the 18th World Medical Association General Assembly, Helsinki, Finland) and its later amendments or comparable ethical standards.

\section{Measures}

\section{Demographic schedule}

Participants were asked to complete a schedule to collect demographics data (e.g., gender, age, years of education, Body Mass Index), with also other information regarding what kind of diet they were on, if/why they were avoiding particular food and if they had another medical or psychological diagnosis.

\section{The Eating Habits Questionnaire (EHQ)}

The EHQ [30-32] is a 21-item self-report questionnaire aimed to assess ON symptoms on a four-point Likert scale ("false, not at all true," "slightly true," "mainly true," and "very true"). It is characterized by three subscales named "Knowledge" (refers to knowledge about healthy eating), "Feelings" (it concerns feelings, emotions, and sensations related to conducting a healthy diet), and "Problems". Based on the initial validation [30], a 3-factor model fit was examined with confirmatory factor analysis. The internal consistency $(0.82<$ Cronbach's $\alpha<0.90)$ and test-retest reliability $(0.72<\mathrm{r}<0.81)$ of the subscales remained good once 14 poorly fitting items were deleted.

The Italian validation [31], both exploratory and confirmatory factorial analysis, evidence the same original EHQ structure [30]. Moreover, a good internal consistency and a one-month test-retest reliability were highlighted ( $\mathrm{r}$ ranging from 0.50 to $0.75 ; 0.001<p<0.01)$. Both the original and Italian versions highlighted adequate internal consistency indices and convergent and divergent validity [30, 31]. Regarding the Polish validation of the EHQ [32], the threefactor structure showed satisfactory goodness-of-fit (comparative fit index $(\mathrm{CFI})=0.99$, root mean square error of approximation $($ RMSEA $)=0.008)$. Reliability analysis for the Polish version of the EHQ across the whole questionnaire showed strong internal consistency $(\alpha=0.88$, intraclass correlation coefficient $(\mathrm{ICC})=0.86)$.

This study showed Italian and Polish samples' adequate reliability (for total and subscales scores, Cronbach's $\alpha$ ranging from 0.70 and 0.92 ).

\section{The Obsessive-Compulsive Inventory-Revised (OCI-R)}

The OCI-R [33-35] is an 18-item self-report questionnaire assessing the Obsessive-Compulsive Disorder (OCD) symptoms on a five-point Likert scale ("Not at all", "A little", "Moderately", "A lot" and "Extremely"). The questionnaire is composed of six subscales ("Washing", "Ordering", "Hoarding", "Mental Neutralizing", "Obsessing”, and "Checking") composing an additional final total score. The original version has put in evidence good reliability and validity indices of the OCI-R, showing strong convergence with established measures of OCD, moderate to high internal consistency across the six subscales, and adequate to high test-retest stability [33]. As regards the Italian version [34], the confirmatory factor analysis showed the original six factors structure. Moreover, a good internal consistency is confirmed $(0.76<$ Cronbach's $\alpha<0.94)$. A 30-day test-retest reliability was good $(0.76<\mathrm{r}<0.99)$ and convergent, discriminant and criterion validity were acceptable [34]. As regards the Polish version [35], the results showed adequate test reliability for the full-scale and subscales scores, high 
internal consistency $(0.62<$ Cronbach's $\alpha<0.85)$, and confirmed satisfactory convergent and divergent validity [36]. In this study, the Italian and Polish self-report questionnaire's good internal consistency is highlighted both for the total and the subscales scores (Cronbach's $\alpha$ ranging from 0.71 and 0.92).

\section{The Multidimensional Perfectionism Scale (MPS)}

The MPS [37-40] is a 35-item self-report questionnaire used to assess perfectionism features on a five-point Likert scale (from "Strongly agree" to "Strongly Disagree"). The MPS is composed of six subscales: "Concern over Mistakes", "Personal Standards", "Parental Expectations", "Parental Criticism", "Doubts about actions", and "Organization". The internal consistency was good $(0.77<$ Cronbach's $\alpha<0.93)$ [37].

Regarding the Italian version [39], the confirmatory factor analysis confirmed the original structure. Moreover, the internal consistency was good $(0.76<$ Cronbach's $\alpha<0.87)$, and the concurrent validity was acceptable. Regarding the Polish version, the adapted version of the MPS most appropriate factor structure contains five correlated factors without the "Organization" subscale. Reliability (Cronbach's $\alpha$ ) of the MPS dimensions ranged from 0.70 to 0.91 [40]. Cronbach's alpha in this study was adequate for the Italian and Polish samples' total and subscales scores (Cronbach's $\alpha$ ranging from 0.85 and 0.92 ).

\section{The Obsessive Beliefs Questionnaire (OBQ)}

The OBQ [41-44] is a self-report questionnaire designed to investigate the core cognitive domains in the origin and maintenance of OCD. The initial 87-item version of the scale (OBQ-87) is composed of six subscales (OCCWG, 2001) highly inter-correlated; for this reason, the OCCWG's [43] empirically derived the OBQ-44 version. The OBQ-44 is composed of six subscales: "Responsibility", "Certainty", "Perfectionism", "Threat estimation", "Control of thoughts", and "Importance of thoughts". Regarding the Polish translation, the OBQ was translated from English to Polish using a standard forward-backward translation procedure. The English version of the OBQ was first translated into Polish (by two translators who independently translated the same questionnaire) and then back-translated into English (by two independent native English speakers without reference to the English original).

Based on the OBQ-87, an Italian 44-item version [44] has been derived for this study to compare Italian and Polish samples. In this study, all subscales demonstrated good internal consistency $(0.88<$ Cronbach's $\alpha<0.97)$ both in the original and derivate versions.

\section{Data analysis}

All analyses were carried out using the SPSS StatisticsVersion 22. First, Cronbach's alpha was investigated for all the administered self-report questionnaires.

Multivariate ANOVA, and ANCOVA, and a Chisquared index were used to explore the differences between groups. Considering the Polish sample's hypothesis had major scores, we have set the alpha level at 0.05 for a one-tailed test. Correlation and partial correlation analysis were used to investigate the relationship between the EHQ and other questionnaires. Finally, Pearson's $r$ correlations have been done to investigate relations between $\mathrm{ON}$ and the other constructs.

\section{Results}

\section{Demographic features of the Polish and Italian university students' samples}

Demographic characteristics of study population are presented in Table 2.

As shown in Table 2, no statistically significant differences emerged for age, gender, and marital status between the Polish and Italian samples. Otherwise, a difference between groups regarding the BMI has been put in evidence; specifically, Polish university students have, on average, a higher Body Mass Index. Polish sample includes a greater number of individuals with chronic disease and a Mood disorder; instead, no differences emerged for the presence of an Anxiety disorder. No differences were put in evidence in the avoidance of food, in using laxatives, and in vomiting. Differences between groups also emerged for the diet type, with the Italian sample composed of a greater number of omnivores, rather than the Polish one, and the Polish group composed of a greater number of fruitarians/vegetarians/vegans.

\section{Invariance's measurement across groups}

The invariance models could be considered adequate. Indeed, although the last analysis concerning the mean invariance is not satisfied, the estimation could be regarded as acceptable. 
Table 2 The main demographic features of the Polish and Italian university students' samples

\begin{tabular}{|c|c|c|c|c|c|}
\hline & Country & $\begin{array}{l}\mathrm{M}(\mathrm{SD}) \\
\text { or } \\
\mathrm{N}(\%)\end{array}$ & $\begin{array}{l}F \\
\text { or } \\
\text { Chi-squared }\end{array}$ & $p$ & $\begin{array}{l}\text { Partial } \\
\eta 2\end{array}$ \\
\hline \multirow[t]{2}{*}{ Age } & Polish sample & $22.33(2.38)$ & 3.67 & 0.06 & 0.006 \\
\hline & Italian sample & $21.98(2.09)$ & & & \\
\hline \multirow[t]{2}{*}{ BMI } & Polish sample & $22.69(4.33)$ & 17.28 & $<0.001$ & 0.03 \\
\hline & Italian sample & $21.43(3.07)$ & & & \\
\hline \multirow{2}{*}{$\begin{array}{l}\text { Gender } \\
\text { (\% female) }\end{array}$} & Polish sample & $236(82.5 \%)$ & 0.79 & 0.38 & 0.04 \\
\hline & Italian sample & $255(79.7 \%)$ & & & \\
\hline \multirow{2}{*}{$\begin{array}{l}\text { Marital status } \\
\text { (\% single) }\end{array}$} & Polish sample & $266(93 \%)$ & 1.42 & 0.23 & 0.05 \\
\hline & Italian sample & $289(90.3 \%)$ & & & \\
\hline \multirow[t]{2}{*}{ Chronic disease } & Polish sample & $53(18.5 \%)$ & 14.43 & $<0.001$ & 0.15 \\
\hline & Italian sample & $26(8.1 \%)$ & & & \\
\hline \multirow[t]{2}{*}{ Mood disorder } & Polish sample & $24(8.4 \%)$ & 13.63 & $<0.001$ & 0.15 \\
\hline & Italian sample & $6(1.9 \%)$ & & & \\
\hline \multirow[t]{2}{*}{ Anxiety disorder } & Polish sample & $21(7.3 \%)$ & 1.06 & 0.30 & 0.04 \\
\hline & Italian sample & $17(5.3 \%)$ & & & \\
\hline \multirow[t]{2}{*}{ Avoidance of food } & Polish sample & $103(36.7 \%)$ & 3.29 & 0.07 & 0.07 \\
\hline & Italian sample & $95(29.7 \%)$ & & & \\
\hline \multirow[t]{2}{*}{ Using laxatives } & Polish sample & $11(3.9 \%)$ & 3.19 & 0.07 & 0.07 \\
\hline & Italian sample & $5(1.6 \%)$ & & & \\
\hline \multirow[t]{2}{*}{ Vomiting } & Polish sample & $10(3.6 \%)$ & 1.02 & 0.31 & 0.04 \\
\hline & Italian sample & $7(2.2 \%)$ & & & \\
\hline \multirow{2}{*}{$\begin{array}{l}\text { Diet type } \\
\text { (omnivores) }\end{array}$} & Polish sample & $188(66.4 \%)$ & $76.18<0.0010 .36$ & & \\
\hline & Italian sample & $297(92.8 \%)$ & & & \\
\hline \multirow{2}{*}{$\begin{array}{l}\text { Diet type } \\
\text { (fruitarians/vegetar- } \\
\text { ians/vegans) }\end{array}$} & Polish sample & $28(9.9 \%)$ & & & \\
\hline & Italian sample & $17(5.3 \%)$ & & & \\
\hline
\end{tabular}

\section{Comparison between Polish and Italian university students in ON, OCD symptoms, core beliefs of OCD, and perfectionism features}

ON, OCD symptoms, core beliefs of OCD, and perfectionism features among university students are presented in Table 3.

Polish sample had, on average, higher scores than the Italian one in the EHQ-21 (total score, "Problems" and "Feelings" scales), the OCI-R (total score, "Hoarding", "Ordering", "Mental Neutralizing", "Washing" and "Checking"), the OBQ (total score, "Responsibility/ Threat estimation" and "Perfectionism/Certainty" scales), and the MPS ("Organization" and "Parental expectations and criticism") $(4,18<F<29,86 ; p<0.05)$.

Instead, the Italian sample had higher scores than the other one in the OCI-R "Obsessing", the OBQ "Importance/Control of Thoughts", and the MPS "Concern over Mistakes/Doubting of Action" (3,13<F<17,41; $p<0.05)$.

\section{Assessment of high versus low level of ON with OCD symptoms and core beliefs of OCD and perfectionism features}

Two groups of individuals (named High-EHQ and LowEHQ, respectively) have been set up: the Italian and the Polish sample separately have been divided according to the EHQ cut-off score. Specifically, the High-EHQ subjects obtained a score equal to or greater than the 90 percentile (Polish group's raw score $>=51$; Italian group's raw score $>=45$ ), while the Low-EHQ individuals were casually extracted from the group with a score less than the 50 percentile (Polish group's raw score $<33$; Italian group's raw score $<32$ ).

A multivariate ANOVA and ANCOVA have been performed considering the two factors "Country" and "Low/ High EHQ" (Table 4) and, as dependent variables, the OCI$\mathrm{R}$, the MPS, and the OBQ total and subscales scores have been considered. Moreover, the BMI effect has been controlled. Significant differences emerged for the single factors 
"Country" ( $F=8.59 ; p<0.001$; partial $\left.\eta^{2}=0.60\right)$, for the "High/Low EHQ" $\left(F=7.34 ; p<0.001\right.$; partial $\left.\eta^{2}=0.56\right)$ and the interaction $\left(F=9.24 ; p<0.001 ;\right.$ partial $\left.\eta^{2}=0.61\right)$.

Specifically, the Polish High-EHQ group, rather than the Italian one, obtained greater scores in the OCI-R total score, the "Hoarding" subscale, the "Mental Neutralization" scale, the "Washing" scale, and the MPS "Parental Expectations/Parental Criticism" scale $(2.52<F<9.29 ; p<0.09$; $0.003<$ partial $\eta^{2}<0.26$ ). Otherwise, the Italian High-EHQ group obtained greater scores in the MPS "Organization" and the "Concern over Mistakes/Doubting of Action" scales $\left(3.56<F<6.64 ; p<0.05 ; 0.12<\right.$ partial $\left.\eta^{2}<0.20\right)$.

Polish Low-EHQ group, rather than the Italian one, obtained greater scores in the OCI-R total score, the "Ordering" subscale, the OBQ total score, the "Perfectionism/ Certainty" scale, the MPS total, the "Concern over Mistakes/Doubting of Action", and the "Parental Expectations/ Parental Criticism" scales $(9.72<F<104.61 ; p<0.001$; $0.02<\operatorname{partial} \eta^{2}<0.79$ ).

Otherwise, the Italian Low-EHQ group, rather than the Polish one, obtained greater scores in the OCI-R "Checking" scale, the "OBQ "Importance/Control of Thoughts" scale, and the MPS "Organization" scale $(12.79<F<193.23$; $p<0.001 ; 0.32<$ partial $\eta^{2}<0.88$ ).

\section{Examination of the relationship between ON, OCD symptoms, core beliefs of $O C D$, and perfectionism features among Polish and Italian university students}

The associations between $\mathrm{ON}$ and investigated variables are shown separately for Polish and Italian university students (Table 5).

In general, correlations are low $(0.13<r<0.28 ; p<0.05)$ as confirmation of partial independence from OCD symptoms and beliefs in both Polish and Italian university students (Table 6).

\section{Discussion}

This study had two main objectives: to examine the differences in ON and OCD symptoms among Polish and Italian university students and to investigate the relationship between ON and OCD symptoms among two samples of university students.

Our findings showed that Polish students have more obsessive and perfectionistic traits and greater feelings and ON's features than Italians. Moreover, for the high and low EHQ groups' multivariate analysis, differences between Polish and Italian emerged and the interaction between ON and culture factors, regardless of the BMI. Polish individuals showed higher levels of OCD symptoms (excepted for 
Table 4 Comparison between the Polish and Italian samples controlling for the BMI effect

\begin{tabular}{|c|c|c|c|c|c|}
\hline & Country & $\mathrm{M}(\mathrm{SD})$ & $F$ & $p$ & Partial $\eta^{2}$ \\
\hline \multirow[t]{2}{*}{ EHQ_Total score } & Polish sample & $34.95(10.54)$ & 4.18 & $<0.05$ & 0.02 \\
\hline & Italian sample & $33.25(8.57)$ & & & \\
\hline \multirow[t]{2}{*}{ EHQ_Knowledge } & Polish sample & $9.46(3.42)$ & 2.44 & ns & 0.01 \\
\hline & Italian sample & $10.12(3.53)$ & & & \\
\hline \multirow[t]{2}{*}{ EHQ_Problems } & Polish sample & $16.39(5.56)$ & 9.46 & $<0.001$ & 0.03 \\
\hline & Italian sample & $14.99(4.24)$ & & & \\
\hline \multirow[t]{2}{*}{ EHQ_Feelings } & Polish sample & $9.10(3.22)$ & 9.93 & $<0.001$ & 0.04 \\
\hline & Italian sample & $8.14(2.55)$ & & & \\
\hline \multirow[t]{2}{*}{ OCI_R_Total score } & Polish sample & $17.81(13.95)$ & 12.86 & $<0.001$ & 0.05 \\
\hline & Italian sample & $13.09(8.66)$ & & & \\
\hline \multirow[t]{2}{*}{ OCI_R_Hoarding } & Polish sample & $3.64(3.00)$ & 6.86 & $<0.01$ & 0.02 \\
\hline & Italian sample & $2.80(2.35)$ & & & \\
\hline \multirow[t]{2}{*}{ OCI_R_Ordering } & Polish sample & $3.62(3.02)$ & 3.62 & $<0.05$ & 0.01 \\
\hline & Italian sample & $2.99(2.53)$ & & & \\
\hline \multirow[t]{2}{*}{ OCI_R_Mental Neutralizing } & Polish sample & $1.44(2.36)$ & 18.63 & $<0.001$ & 0.06 \\
\hline & Italian sample & $0.63(1.35)$ & & & \\
\hline \multirow[t]{2}{*}{ OCI_R_Washing } & Polish sample & $2.73(2.76)$ & 26.05 & $<0.001$ & 0.09 \\
\hline & Italian sample & $1.38(1.92)$ & & & \\
\hline \multirow[t]{2}{*}{ OCI_R_Obsessing } & Polish sample & $2.47(2.92)$ & 3.13 & $<0.05$ & 0.01 \\
\hline & Italian sample & $3.11(2.97)$ & & & \\
\hline \multirow[t]{2}{*}{ OCI_R_Checking } & Polish sample & $3.90(3.39)$ & 26.24 & $<0.001$ & 0.09 \\
\hline & Italian sample & $2.19(2.18)$ & & & \\
\hline \multirow[t]{2}{*}{ OBQ_Total score } & Polish sample & $141.95(47.56)$ & 5.97 & $<0.01$ & 0.02 \\
\hline & Italian sample & $129.69(40.62)$ & & & \\
\hline \multirow[t]{2}{*}{ OBQ_RT } & Polish sample & $53.23(18.09)$ & 20.60 & $<0.001$ & 0.07 \\
\hline & Italian sample & $44.40(15.19)$ & & & \\
\hline \multirow[t]{2}{*}{ OBQ_PC } & Polish sample & $57.13(20.13)$ & 12.52 & $<0.001$ & 0.04 \\
\hline & Italian sample & $49.56(15.64)$ & & & \\
\hline \multirow[t]{2}{*}{ OBQ_ICT } & Polish sample & $31.59(13.80)$ & 6.82 & $<0.01$ & 0.02 \\
\hline & Italian sample & 35.73 (13.66) & & & \\
\hline \multirow[t]{2}{*}{ MPS_Total score } & Polish sample & $100.20(22.26)$ & 0.26 & ns & 0.001 \\
\hline & Italian sample & 98.95 (19.91) & & & \\
\hline \multirow[t]{2}{*}{ MPS_PS } & Polish sample & $22.43(6.13)$ & 1.13 & ns & 0.004 \\
\hline & Italian sample & $21.69(5.50)$ & & & \\
\hline \multirow[t]{2}{*}{ MPS_O } & Polish sample & $23.20(4.98)$ & 5.80 & $<0.01$ & 0.02 \\
\hline & Italian sample & $21.93(5.15)$ & & & \\
\hline \multirow[t]{2}{*}{ MPS_CMD } & Polish sample & $33.21(11.89)$ & 17.41 & $<0.001$ & 0.06 \\
\hline & Italian sample & 38.97 (10.94) & & & \\
\hline \multirow[t]{2}{*}{ MPS_PEPC } & Polish sample & $21.36(8.44)$ & 29.86 & $<0.001$ & 0.10 \\
\hline & Italian sample & $16.36(6.91)$ & & & \\
\hline
\end{tabular}

$E H Q$ Eating Habits Questionnaire, OCI-R Obsessive Compulsive Inventory-Revised, $O B Q$ Obsessive Beliefs Questionnaire, $O B Q \_R T$ Obsessive Beliefs Questionnaire - Responsibility/Threat estimation, $O B Q \_P C$ Obsessive Beliefs Questionnaire - Perfectionism/Certainty, OBQ_ICT Obsessive Beliefs Questionnaire - Importance/Control of Thoughts, MPS Multidimensional Perfectionism Scale, MPS_PS Multidimensional Perfectionism Scale - Personal Standard, MPS_O Multidimensional Perfectionism Scale - Organization, MPS_CMD Multidimensional Perfectionism Scale - Concern over Mistakes/Doubting of Action, MPS_PEPC Multidimensional Perfectionism Scale - Parental Expectations/Parental Criticism the Obsessing and Checking scales), core beliefs (excepted for the "ICT" scale), and perfectionistic traits (excepted for the "Organization" scale). To understand in more detail the impact of the Country factor, we have also compared, respectively, Polish and Italian students with higher ON scores and Polish and Italian ones with lower scores: Polish 
Table 5 Assessment of high versus low level of $\mathrm{ON}$ with OCD symptoms and core beliefs of OCD and perfectionism features: comparison between Polish and Italian samples

\begin{tabular}{|c|c|c|c|}
\hline & $\begin{array}{l}\text { Country } \\
\text { (Polish: } N=49 \text {; Italian: } \\
N=64)\end{array}$ & $\begin{array}{l}\text { Low/High EHQ } \\
(\text { Low }=58 ; \\
\text { High }=55)\end{array}$ & $M(\mathrm{SD})$ \\
\hline \multirow[t]{8}{*}{ OCI_R Total score } & \multirow[t]{3}{*}{ Polish sample } & Low & $16.88(11.55)$ \\
\hline & & High & $23.46(17.19)$ \\
\hline & & Total & $20.10(14.81)$ \\
\hline & \multirow[t]{3}{*}{ Italian sample } & Low & $2.88(3.12)$ \\
\hline & & High & $17.32(11.45)$ \\
\hline & & Total & $9.88(10.97)$ \\
\hline & \multirow[t]{2}{*}{ Total } & Low & $8.91(10.52)$ \\
\hline & & High & $20(14.43)$ \\
\hline \multirow[t]{8}{*}{ OCI_R_Hoarding } & \multirow[t]{3}{*}{ Polish sample } & Low & $3.60(2.97)$ \\
\hline & & High & $4.58(2.93)$ \\
\hline & & Total & $4.08(2.96)$ \\
\hline & \multirow[t]{3}{*}{ Italian sample } & Low & $2.58(2.68)$ \\
\hline & & High & $2.74(2.31)$ \\
\hline & & Total & $2.66(2.49)$ \\
\hline & \multirow[t]{2}{*}{ Total } & Low & $3.02(2.83)$ \\
\hline & & High & $3.55(2.73)$ \\
\hline \multirow[t]{8}{*}{ OCI_R_Ordering } & \multirow[t]{3}{*}{ Polish sample } & Low & $3.04(2.3)$ \\
\hline & & High & $4.33(3.20)$ \\
\hline & & Total & $3.0 /(2.82)$ \\
\hline & \multirow[t]{3}{*}{ Italian sample } & Low & $0.52(0.97)$ \\
\hline & & High & $3.87(2.71)$ \\
\hline & & Total & $2.14(2.61)$ \\
\hline & \multirow[t]{2}{*}{ Total } & Low & $1.60(2.09)$ \\
\hline & & High & $4.07(2.91)$ \\
\hline \multirow[t]{8}{*}{ OCI_R_Mental Neutralizing } & \multirow[t]{3}{*}{ Polish sample } & Low & $0.92(1.35)$ \\
\hline & & High & $2.92(3.72)$ \\
\hline & & Total & $1.90(2.92)$ \\
\hline & \multirow[t]{3}{*}{ Italian sample } & Low & $1.52(2.06)$ \\
\hline & & High & $1.03(1.80)$ \\
\hline & & Total & $1.28(1.94)$ \\
\hline & \multirow[t]{2}{*}{ Total } & Low & $1.26(1.80)$ \\
\hline & & High & $1.85(2.93)$ \\
\hline \multirow[t]{8}{*}{ OCI_R_Washing } & \multirow[t]{3}{*}{ Polish sample } & Low & $2.68(2.69)$ \\
\hline & & High & $4.04(3.58)$ \\
\hline & & Total & $3.35(3.20)$ \\
\hline & \multirow[t]{3}{*}{ Italian sample } & Low & $2.39(2.21)$ \\
\hline & & High & $2.16(2.93)$ \\
\hline & & Total & $2.28(2.57)$ \\
\hline & \multirow[t]{2}{*}{ Total } & Low & $2.52(2.41)$ \\
\hline & & High & $2.98(3.34)$ \\
\hline \multirow[t]{8}{*}{ OCI_R_Obsessing } & \multirow[t]{3}{*}{ Polish sample } & Low & $2.40(2.48)$ \\
\hline & & High & $3.58(3.32)$ \\
\hline & & Total & $2.98(2.95)$ \\
\hline & \multirow[t]{3}{*}{ Italian sample } & Low & $1.91(2.43)$ \\
\hline & & High & $4.74(3.92)$ \\
\hline & & Total & $3.28(3.52)$ \\
\hline & Total & Low & $2.12(2.44)$ \\
\hline & & High & $4.24(3.69)$ \\
\hline
\end{tabular}


Table 5 (continued)

\begin{tabular}{|c|c|c|c|}
\hline & $\begin{array}{l}\text { Country } \\
\text { (Polish: } N=49 \text {; Italian: } \\
N=64 \text { ) }\end{array}$ & $\begin{array}{l}\text { Low/High EHQ } \\
(\text { Low }=58 ; \\
\text { High }=55)\end{array}$ & $M(\mathrm{SD})$ \\
\hline \multirow[t]{8}{*}{ OCI_R_Checking } & \multirow[t]{3}{*}{ Polish sample } & Low & \multirow{3}{*}{$\begin{array}{l}4.24(3.42) \\
4(3.44) \\
4.12(3.40)\end{array}$} \\
\hline & & High & \\
\hline & & Total & \\
\hline & \multirow[t]{3}{*}{ Italian sample } & Low & \multirow{3}{*}{$\begin{array}{l}24.94(5.24) \\
2.77(2.99) \\
14.20(11.95)\end{array}$} \\
\hline & & High & \\
\hline & & Total & \\
\hline & \multirow[t]{2}{*}{ Total } & Low & $16.02(11.28)$ \\
\hline & & High & $3.31(3.22)$ \\
\hline \multirow[t]{8}{*}{ OBQ_Total score } & \multirow[t]{3}{*}{ Polish sample } & Low & $140.72(50.51)$ \\
\hline & & High & $145.92(45.50)$ \\
\hline & & Total & $143.27(47.69)$ \\
\hline & \multirow[t]{3}{*}{ Italian sample } & Low & 93.55 (21.87) \\
\hline & & High & $148(48.05)$ \\
\hline & & Total & $119.92(45.77)$ \\
\hline & \multirow[t]{2}{*}{ Total } & Low & $113.88(43.57)$ \\
\hline & & High & $147.09(46.53)$ \\
\hline \multirow[t]{8}{*}{ OBQ_RT } & \multirow[t]{3}{*}{ Polish sample } & Low & $52.32(20.08)$ \\
\hline & & High & $54.88(17.69)$ \\
\hline & & Total & $53.57(18.79)$ \\
\hline & \multirow[t]{3}{*}{ Italian sample } & Low & $46.18(16.05)$ \\
\hline & & High & $49.69(18.13)$ \\
\hline & & Total & $47.88(17.04)$ \\
\hline & \multirow[t]{2}{*}{ Total } & Low & $48.83(17.99)$ \\
\hline & & High & $51.95(17.96)$ \\
\hline \multirow[t]{8}{*}{ OBQ_PC } & \multirow[t]{3}{*}{ Polish sample } & Low & $57.28(22.20)$ \\
\hline & & High & $55.92(18.12)$ \\
\hline & & Total & $50.01(20.10)$ \\
\hline & \multirow[t]{3}{*}{ Italian sample } & Low & $36.30(13.58)$ \\
\hline & & High & $56.84(16.34)$ \\
\hline & & Total & $46.25(18.10)$ \\
\hline & \multirow[t]{2}{*}{ Total } & Low & $45.34(20.51)$ \\
\hline & & High & $56.44(16.98)$ \\
\hline \multirow[t]{8}{*}{ OBQ_ICT } & \multirow[t]{3}{*}{ Polish sample } & Low & $31.12(12.85)$ \\
\hline & & High & $35.13(13.75)$ \\
\hline & & Total & \\
\hline & \multirow[t]{3}{*}{ Italian sample } & Low & $121.61(42)$ \\
\hline & & High & $41.47(17.92)$ \\
\hline & & Total & $82.79(51.75)$ \\
\hline & \multirow[t]{2}{*}{ Total } & Low & $82.60(55.71)$ \\
\hline & & High & $38.70(16.40)$ \\
\hline \multirow[t]{8}{*}{ MPS_Total score } & Polish sample & Low & $98.08(26.91)$ \\
\hline & & High & $104.33(19.82)$ \\
\hline & & Total & $101.14(23.67)$ \\
\hline & Italian sample & Low & $23(14.75)$ \\
\hline & & High & $110.39(19.00)$ \\
\hline & & Total & $65.33(47.12)$ \\
\hline & Total & Low & $55.36(42.82)$ \\
\hline & & High & $107.75(19.42)$ \\
\hline
\end{tabular}


Table 5 (continued)

\begin{tabular}{|c|c|c|c|}
\hline & $\begin{array}{l}\text { Country } \\
\text { (Polish: } N=49 \text {; Italian: } \\
N=64)\end{array}$ & $\begin{array}{l}\text { Low/High EHQ } \\
\text { (Low =58; } \\
\text { High }=55)\end{array}$ & $M(\mathrm{SD})$ \\
\hline \multirow[t]{8}{*}{ MPS_PS } & \multirow[t]{3}{*}{ Polish sample } & Low & $21.52(7.00)$ \\
\hline & & High & $\begin{array}{l}24.13(5.69) \\
22.80(6.46)\end{array}$ \\
\hline & & Total & \\
\hline & \multirow[t]{3}{*}{ Italian sample } & Low & $21.21(5.30)$ \\
\hline & & High & $\begin{array}{l}23.65(4.89) \\
22.39(5.21)\end{array}$ \\
\hline & & Total & \\
\hline & \multirow[t]{2}{*}{ Total } & Low & $21.34(6.04)$ \\
\hline & & High & $23.85(5.21)$ \\
\hline \multirow[t]{8}{*}{ MPS_O } & \multirow[t]{3}{*}{ Polish sample } & Low & $22.88(5.73)$ \\
\hline & & High & $21.83(5.53)$ \\
\hline & & Total & $22.37(5.60)$ \\
\hline & \multirow[t]{3}{*}{ Italian sample } & Low & $35.09(11.36)$ \\
\hline & & High & 24.84 (3.49) \\
\hline & & Total & $30.13(9.90)$ \\
\hline & \multirow[t]{2}{*}{ Total } & Low & $29.83(11.11)$ \\
\hline & & High & 23.53 (4.70) \\
\hline \multirow[t]{8}{*}{ MPS_CMD } & \multirow[t]{3}{*}{ Polish sample } & Low & $32.04(13.76)$ \\
\hline & & High & $35.04(11.20)$ \\
\hline & & Total & $33.51(12.53)$ \\
\hline & \multirow[t]{3}{*}{ Italian sample } & Low & $14.91(7.21)$ \\
\hline & & High & $43.13(10.94)$ \\
\hline & & Total & $28.58(16.89)$ \\
\hline & \multirow[t]{2}{*}{ Total } & Low & $22.29(13.50)$ \\
\hline & & High & 39.60 (11.67) \\
\hline \multirow[t]{8}{*}{ MPS_PEPC } & \multirow[t]{3}{*}{ Polish sample } & Low & $21.64(7.51)$ \\
\hline & & High & 23.33 (9.68) \\
\hline & & Total & $22.47(8.59)$ \\
\hline & \multirow[t]{3}{*}{ Italian sample } & Low & $3.03(3.74)$ \\
\hline & & High & $18.77(8.01)$ \\
\hline & & Total & $10.66(10.03)$ \\
\hline & \multirow[t]{2}{*}{ Total } & Low & $11.05(10.86)$ \\
\hline & & High & $20.76(8.99)$ \\
\hline
\end{tabular}

OCI-R = Obsessive Compulsive Inventory-Revised; OBQ=Obsessive Beliefs Questionnaire; OBQ_ $\mathrm{RT}=$ Obsessive Beliefs Questionnaire - Responsibility/Threat estimation; OBQ_PC $=$ Obsessive Beliefs Questionnaire - Perfectionism/Certainty; OBQ_ICT = Obsessive Beliefs Questionnaire - Importance/ Control of Thoughts; MPS = Multidimensional Perfectionism Scale; MPS_PS $=$ Multidimensional Perfectionism Scale - Personal Standard; MPS_O=Multidimensional Perfectionism Scale-Organization; MPS_CMD = Multidimensional Perfectionism Scale - Concern over Mistakes/Doubting of Action; MPS_ $\mathrm{PEPC}=$ Multidimensional Perfectionism Scale - Parental Expectations/Parental Criticism

students, both with lower and higher ON, shown more obsessive and compulsive features than the other groups and, for all these reasons, we could affirm that the first hypothesis was confirmed.

In line with these results finding that Polish students displayed higher levels of orthorexic eating behavior than Italian students, recent studies have shown higher $\mathrm{ON}$ behaviors in the Polish sample than Italian ones (82\% vs.
$46 \%$ [29]; $66.5 \%$ vs. $30.9 \%$ [31]). The Mediterranean diet, dominant in Italy, has long been considered one of the world's healthiest and to have been linked with several health benefits [28]. In contrast, in Poland, over the past decades, economic and political changes have influenced the lifestyle-related behaviors of various social groups, especially on young people [28], and a new trend seems to focus on the health aspects of food choices [45]. Control 
Table 6 Correlations considering Polish and Italian samples

\begin{tabular}{|c|c|c|c|c|c|}
\hline & $\mathrm{R}$ & $\begin{array}{l}\text { EHQ } \\
\text { Total score }\end{array}$ & $\begin{array}{l}\text { EHQ } \\
\text { Knowledge }\end{array}$ & $\begin{array}{l}\text { EHQ } \\
\text { Problems }\end{array}$ & $\begin{array}{l}\text { EHQ } \\
\text { Feelings }\end{array}$ \\
\hline OCI_R_total score & Polish/Italian & $0.13 * / 0.22 * * *$ & $0.02 / 0.11$ & $0.17 * / 0.23 * * *$ & $0.10 / 0.22 * *$ \\
\hline OCI_R_Hoarding & Polish/Italian & $0.13 * / 0.05$ & $0.03 /-0.02$ & $0.14 * / 0.03$ & $0.14 * / 0.14 *$ \\
\hline OCI_R_Ordering & Polish/Italian & $0.10 / 0.18^{* *}$ & $0.01 / 0.15^{*}$ & $0.12 / 0.18 * *$ & $0.11 / 0.10$ \\
\hline OCI_R_MN & Polish/Italian & $0.18 * * / 0.11$ & $0.08 /-0.01$ & $0.25 * * / 0.17 * *$ & $0.06 / 0.09$ \\
\hline OCI_R_Washing & Polish/Italian & $0.13 * * / 0.19 * *$ & $0.03 / 0.13^{*}$ & $0.21 * * / 0.17 * *$ & $0.03 / 0.19 * *$ \\
\hline OCI_R_Obsessing & Polish/Italian & $0.08 / 0.19^{* *}$ & $-0.02 / 0.09$ & $0.13 * / 0.19 * *$ & $0.05 / 0.20 * *$ \\
\hline OCI_R_Checking & Polish/Italian & $0.03 / 0.13 *$ & $-0.02 / 0.05$ & $0.03 / 0.16^{* *}$ & $0.08 / 0.12 *$ \\
\hline OBQ_TOT score & Polish/Italian & $0.03 / 0.17 * *$ & $-0.03 / 0.05$ & $0.05 / 0.17 * *$ & $0.04 / 0.23 * * *$ \\
\hline OBQ_RT & Polish/Italian & $0.05 / 0.12 *$ & $0.01 / 0.01$ & $0.04 / 0.11^{*}$ & $0.07 / 0.18 * *$ \\
\hline OBQ_PC & Polish/Italian & $-0.03 / 0.19 * *$ & $-0.06 / 0.11$ & $-0.02 / 0.17 * *$ & $0.01 / 0.22 * * *$ \\
\hline OBQ_ICT & Polish/Italian & $0.08 / 0.15^{*}$ & $-0.01 / 0.01$ & $0.14 * / 0.17 * *$ & $0.03 / 0.21 * * *$ \\
\hline MPS_TOT & Polish/Italian & $0.12 / 0.28 * * *$ & $0.05 / 0.18^{* *}$ & $0.15 * / 0.27 * * *$ & $0.10 / 0.26^{* * *}$ \\
\hline MPS_PS & Polish/Italian & $0.15 * / 21 * *$ & $0.15 * / 0.19 * * *$ & $0.12 / 0.15^{* *}$ & $0.13 / 0.18^{*}$ \\
\hline MPS_O & Polish/Italian & $-0.01 / 0.18 * * *$ & $0.05 / 0.22 * * *$ & $-0.08 / 0.14^{*}$ & $0.07 / 0.07$ \\
\hline MPS_CMD & Polish/Italian & $0.09 / 0.21 * * *$ & $-0.03 / 0.11$ & $0.15 * / 0.21 * * *$ & $0.05 / 0.22 * * *$ \\
\hline MPS_PEPC & Polish/Italian & $0.09 / 0.18 * * *$ & $0.03 / 0.04$ & $0.13 * / 0.21 * * *$ & $0.05 / 0.20 * * *$ \\
\hline
\end{tabular}

$E H Q$ Eating Habits Questionnaire, OCI-R Obsessive Compulsive Inventory-Revised, $O B Q$ Obsessive Beliefs Questionnaire, $O B Q \_R T$ Obsessive Beliefs Questionnaire - Responsibility/Threat estimation, $O B Q \_P C$ Obsessive Beliefs Questionnaire - Perfectionism/Certainty, OBQ_ICT Obsessive Beliefs Questionnaire - Importance/Control of Thoughts, MPS Multidimensional Perfectionism Scale, MPS_PS Multidimensional Perfectionism Scale - Personal Standard, MPS_O Multidimensional Perfectionism Scale - Organization, MPS_CMD Multidimensional Perfectionism Scale - Concern over Mistakes/Doubting of Action, MPS_PEPC Multidimensional Perfectionism Scale - Parental Expectations/Parental Criticism

$* p<0.05 ; * * p<0.01 * * * p<0.001$ of the composition of food products and the belief that healthy dieting is the most important approach for improving one's health could explain the higher levels of ON found in the Polish sample. On the other hand, likely, that the lowest frequency of $\mathrm{ON}$ and attitudes found in the Italian sample depends on an enogastronomic culture that includes the Mediterranean diet style [20].

The preset study's second objective was to evaluate the ON level (high versus low) with OCD symptoms and core beliefs of OCD and perfectionism. Our results demonstrated that students having a higher level of ON exhibited higher levels of OCD symptoms (excepted for the Hoarding, the Mental Neutralizing, and the Washing scales), OCD core beliefs (excepted for the "Responsibility/Threat estimation" scale), and perfectionism (excepted for the "Personal Standard" scale $)(6.91<F<201.21$; $p<0.01$; partial $\left.\eta^{2}<0.79\right)$. Based on these data, the second hypothesis was confirmed. Our findings concur with other studies showing that participants with ON features had a significantly higher level of OCD symptoms and beliefs [27]. Obsessive and compulsive behaviors were more pronounced in ON, and more than about $30 \%$ of ON subjects fulfilled criteria for clinically relevant OCD symptoms (compared to $11.2 \%$ in non-ON) [14].
Based on our knowledge, this is the first study that analyzed this relation, and for this reason, future studies have been realized for further investigation.

The third objective of the present study was to investigate the relationship between $\mathrm{ON}$ and $\mathrm{OCD}$ symptoms, core beliefs of OCD, and perfectionism among Polish and Italian university students. Our results showed that, in general, correlations were low $(-0.08<r<0.12 ; p<0.05)$ as confirmation of partial independence ON from OCD symptoms and core beliefs of OCD in both Polish and Italian university students (H3 was partially confirmed). These results suggest that obsessive symptomatology could be considered an $\mathrm{ON}$ epiphenomenon. Moreover, ON seems similar to OCD for repetitively, intrusively, and rigidity behaviors and consequences (e.g., wasting time). Our findings are consistent with other studies revealing that greater ON symptomatology is associated with greater levels of OCD symptoms [17, $22,24,25,30,46]$, confirming that an association does exist and may mean that ON symptoms and OCD symptoms are comorbid. The longitudinal study could answer the question of whether ON tendencies, at some point in time, may prompt a person to develop routine, repetitive behaviors [21] as well as to develop "pure" diets [46] and may ultimately lead to OCD like-behavior. 
In the previous study [46], checking and dressing/grooming compulsions showed ON's most significant correlations, suggesting parallel cognitive processes with the ritualistic compulsions. The dressing/grooming compulsions represent the urge to insist on doing hygiene steps in a fixed sequence. If the sequence is interrupted, patients may again start initially, which suggests a phenomenological similarity with the ritualistic behavior of preparing food in people with $\mathrm{ON}$ [46]. Our results contrast to previous findings: first, no relationships between ON and OCD (except for checking) have been shown. These data confirm the hypothesis that $\mathrm{ON}$ and OCD are two different clinical syndromes [47] and show that knowledge of healthy eating has slight negative correlations with OCD symptoms and problems related to ON moderately correlated with OCD symptoms [48].

We found weak and moderate associations between ON and perfectionism features, especially considering the Italian sample. Recent studies have also demonstrated that perfectionism was positively correlated with greater $\mathrm{ON}$ symptomatology among university students [19, 25, 49]. Besides, all components of perfectionism were significantly correlated and predicted ON problems. Only the tendency of individuals to set excessively high standards for themselves ("personal standards and organization") was significantly correlated with behaviors and feelings related to ON [49]. Perfectionism, setting high expectations and standards, worrying, fear, or doubtfulness about the future, being emotionally restrained, or demonstrating intrusive feelings/thoughts and repetitive behavior could be determinants of orthorexic behaviors [8].

The current study has limitations. The first is sampling bias - our sample (university students) does not reflect the general population's characteristics. In addition, the selection of university students was not randomized. Selfreported data cannot be independently verified and may lead to inaccuracies (e.g., social desirability bias). A crosssectional study design does not evaluate causality due to the non-temporal nature of the study design. Online questionnaires could have decreased participant recruitment's internal validity. Students' awareness in participating in the study can also influence outcomes (Hawthorne effect) [50]. Finally, the non-validated version of the OBQ based on the Polish population should be considered a limitation of the present study.

\section{Conclusion}

The present results demonstrated that $\mathrm{ON}$ is related to $\mathrm{OCD}$ symptoms and perfectionism features. Further investigations regarding the correlates of $\mathrm{ON}$ across different cultural groups are still needed. Moreover, it is important to identify whether ON is similar or different from other disorders (e.g.,
AN and OCD). Moreover, further studies should include three clinical subgroups, respectively, diagnosed with ON, $\mathrm{AN}$, and $\mathrm{OCD}$, so this could resolve the debate on the nature of $\mathrm{ON}$ and its treatment. Our findings may suggest screening for OCD symptomology as a comorbid problem among individuals with $\mathrm{ON}$.

Longitudinal studies are also needed to assess the ON develops; if it develops independently, it is a prelude or a result of AN recovery or a variant of the OCD spectrum. More studies are needed comparing those who only have ON and individuals with OCD to evaluate how psychological and clinical profiles are similar amongst the ON and OCD.

\section{What is already known on this subject?}

Based on the literature, ON shares several characteristics with other psychological disorders, including Obsessive-Compulsive Disorder [27].

Nowadays, no definitive conclusions can be drawn. Therefore, it is important to investigate cross-cultural differences in ON, OCD symptoms, core beliefs of OCD and perfectionism features, to assess the level of ON with OCD symptoms and core beliefs of OCD, and to examine the relationship between ON, OCD symptoms, core beliefs of OCD and perfectionism features.

\section{What your study adds?}

Our study demonstrated ON's partial independence from OCD symptoms and core beliefs of OCD in both Polish and Italian university students.

Acknowledgements The first author (AB-M) acknowledges the financial support by the "Excellence Initiative - Research University" program for the years 2020-2026 for the University of Wroclaw. The authors (SP and CN) express their thanks to Lisa D'Agaro for tools administration.

Authors' contributions $\mathrm{ABM}$ and $\mathrm{CN}$ designed, directed, and supervised the project, devised the main conceptual ideas, contributed to interpreting the results, wrote and reviewed the manuscript. SP did data analysis and reviewed the article. JM, AM, PS, and KCB cooperated in the data collection.

Funding This research did not receive any specific grant from funding agencies in the public, commercial, or not-for-profit sectors.

\section{Declaration}

Conflict of interest The authors also declare that they have no known competing financial interests or personal relationships that could have influenced the work reported in this paper. 
Ethical approval This study was performed following the Declaration of Helsinki (adopted by the 18th World Medical Association General Assembly, Helsinki, Finland) and its later amendments or comparable ethical standards. A research ethics committee approved it (no. WKEB59/05/2019 in Poland and no. 3067-14/06/2019 in Italy).

Informed consent Informed consent was obtained from each voluntary participant before his or her enrollment in the study.

Open Access This article is licensed under a Creative Commons Attribution 4.0 International License, which permits use, sharing, adaptation, distribution and reproduction in any medium or format, as long as you give appropriate credit to the original author(s) and the source, provide a link to the Creative Commons licence, and indicate if changes were made. The images or other third party material in this article are included in the article's Creative Commons licence, unless indicated otherwise in a credit line to the material. If material is not included in the article's Creative Commons licence and your intended use is not permitted by statutory regulation or exceeds the permitted use, you will need to obtain permission directly from the copyright holder. To view a copy of this licence, visit http://creativecommons.org/licenses/by/4.0/.

\section{References}

1. Ambwani S, Shippe M, Gao Z, Austin SB (2019) Is clean eating a healthy or harmful dietary strategy? Perceptions of clean eating and associations with disordered eating among young adults. J Eat Disord 7(1):1-14. https://doi.org/10.1186/ s40337-019-0246-2

2. Vuillier L, Robertson S, Greville-Harris M (2020) Orthorexic tendencies are linked with difficulties with emotion identification and regulation. J Eat Disord 8:15. https://doi.org/10.1186/ s40337-020-00291-7

3. Greville-Harris M, Smithson J, Karl A (2019) What are people's experiences of Orthorexia Nervosa? A qualitative study of online blogs. Eat Weight Disord. https://doi.org/10.1007/ s40519-019-00809-2

4. Bratman S (1997) Health food junkie. Yoga J 136:42-50

5. Cena H, Barthels F, Cuzzolaro M, Bratman S, Brytek-Matera A, Dunn T, Varga M, Missbach B, Donini LM (2019) Definition and diagnostic criteria for Orthorexia Nervosa: a narrative review of the literature. Eat Weight Disord 24(2):209-246. https://doi.org/ 10.1007/s40519-018-0606-y

6. Bratman S, Knight D (2000) Health food junkies: overcoming the obsession with healthful eating. Broadway Books, New York

7. Dunn TM, Bratman S (2016) On Orthorexia Nervosa: a review of the literature and proposed diagnostic criteria. Eat Behav 21:1117. https://doi.org/10.1016/j.eatbeh.2015.12.006

8. Bratman S (2017) Orthorexia vs. theories of healthy eating. Eat Weight Disord 22(3):381-385. https://doi.org/10.1007/ s40519-017-0417-6

9. Brytek-Matera A (2012) Orthorexia Nervosa: an eating disorder, Obsessive Compulsive Disorder or disturbed eating habit. Arch Psychiatry Psychother 1(1):55-60

10. Dell'Osso L, Abelli M, Carpita B, Massimetti G, Pini S, Rivetti L, Gorrasi F, Tognetti R, Ricca V, Carmassi C (2016) Orthorexia Nervosa in a sample of Italian university population. Riv Psichiatr 51(5):190-196. https://doi.org/10.1708/2476.25888

11. Koven NS, Abry AW (2015) The clinical basis of Orthorexia Nervosa: emerging perspectives. Neuropsychiatr Dis Treat 11:385394. https://doi.org/10.2147/NDT.S61665
12. McComb SE, Mills JS (2019) Orthorexia Nervosa: a review of psychosocial risk factors. Appetite 140:50-75. https://doi.org/10. 1016/j.appet.2019.05.005

13. Kummer A, Dias FM, Teixeira AL (2008) On the concept of orthorexia nervosa. Scand J Med Sci Sports 18(3):395-397. https:// doi.org/10.1111/j.1600-0838.2008.00809.x

14. Strahler J, Hermann A, Walter B, Stark R (2018) Orthorexia Nervosa: A behavioral complex or a psychological condition? J Behav Addict 7(4):1143-1156. https://doi.org/10.1556/2006.7.2018.129

15. Donini L, Marsili D, Graziani M, Imbriale M, Cannella C (2004) Orthorexia Nervosa: A preliminary study with a proposal for diagnosis and an attempt to measure the dimension of the phenomenon. Eat Weight Disord 9(2):151-157. https://doi.org/10.1007/ BF03325060

16. Asil E, Sürücüoğlu MS (2015) Orthorexia Nervosa in Turkish dietitians. Ecol Food Nutr 54(4):303-313. https://doi.org/10.1080/ 03670244.2014.987920

17. Arusoğlu G, Kabakçi E, Köksal G, Merdol TK (2008) Orthorexia Nervosa and adaptation of ORTO-11 into Turkish. Turk J Psychiatry 19(3):283-291 (PMID: 18791881)

18. Barthels F, Meyer F, Huber T, Pietrowsky R (2017) Analyse des orthorektischen Ernährungsverhaltens von Patienten mit Essstörungen und mit Zwangsstörungen [Analysis of orthorexic eating behavior in patients with eating disorder and obsessivecompulsive disorder]. Z Klin Psychol Psychother 46(1):32-41. https://doi.org/10.1026/1616-3443/a000399

19. Brytek-Matera A, Fonte MA, Poggiogalle E, Donini LM, Cena H (2017) Orthorexia Nervosa: relationship with obsessive-compulsive symptoms, disordered eating patterns and body uneasiness among Italian university students. Eat Weight Disord 22:609-617. https://doi.org/10.1007/s40519-017-0427-4

20. Gramaglia C, Gambaro E, Delicato C, Marchetti M, Sarchiapone M, Ferrante D, Roncero M, Perpiñá C, Brytek-Matera A, Wojtyna E, Zeppegno P (2019) Orthorexia Nervosa, eating patterns and personality traits: a cross-cultural comparison of Italian, Polish and Spanish university students. BMC Psychiatry 19:235. https:// doi.org/10.1186/s12888-019-2208-2

21. Costa CB, Hardan-Khalil K (2019) Orthorexia nervosa and obsessive-compulsive behaviour among college students in the United States. J Nurs Educ Pract 9(2):67-75. https://doi.org/10.5430/ jnep.v9n2p67

22. Koven NS, Senbonmatsu R (2013) A neuropsychological evaluation of Orthorexia Nervosa. Open J Psychiatry 3(2):214-222. https://doi.org/10.4236/ojpsych.2013.32019

23. Murphy R, Nutzinger DO, Paul T, Leplow B (2004) Conditionalassociative learning in eating disorders: a comparison with OCD. J Clin Exp Neuropsychol 26(2):190-199. https://doi.org/10.1076/ jcen.26.2.190.28091

24. Bundros J, Clifford D, Silliman K, Morris MN (2016) Prevalence of Orthorexia Nervosa among college students based on Bratman's test and associated tendencies. Appetite 101:86-94. https:// doi.org/10.1016/j.appet.2016.02.144

25. Hayes O, Wu MS, De Nadai AS, Storch EA (2017) Orthorexia Nervosa: an examination of the prevalence, correlates, and associated impairment in a university sample. J Cogn Psychother 31(2):124-135. https://doi.org/10.1891/0889-8391.31.2.124

26. Koinig I (2021) Designing COVID-19 campaigns to achieve individual compliance: examples from Austria, the U.S., and Australia. In: Sari, G (ed) Handbook of research on representing health and medicine in modern media. IGI Global, pp 367-391

27. Vaillancourt C, Bédard A, Bélanger-Gravel A, Provencher V, Bégin C, Desroches S, Lemieux S (2019) Promoting healthy eating in adults: an evaluation of pleasure-oriented versus healthoriented messages. Curr Dev Nutr 3(5):12. https://doi.org/10. $1093 / \mathrm{cdn} / \mathrm{nzz} 012$ 
28. Schwingshackl L, Missbach B, Hoffmann KJ (2015) Adherence to a Mediterranean diet and risk of diabetes: a systematic review and meta-analysis. Public Health Nutr 18(7):1292-1299. https://doi. org/10.1017/S1368980014001542 (Epub 2014 Aug 22 PMID: 25145972)

29. Gramaglia C, Brytek-Matera A, Rogoza R, Zeppegno P (2017) Orthorexia and anorexia nervosa: two distinct phenomena? A cross-cultural comparison of orthorexic behaviours in clinical and non-clinical samples. BMC Psychiatry 17:75. https://doi.org/10. 1186/s12888-017-1241-2

30. Gleaves DH, Graham EC, Ambwani S (2013) Measuring "orthorexia": development of the Eating Habits Questionnaire. Int $\mathrm{J}$ Educ Psychol Assess 12(2):1-18

31. Novara C, Pardini S, Pastore M, Mulatti C (2017) Ortoressia Nervosa: Un'indagine del costrutto e delle caratteristiche psicometriche della versione italiana dell'Eating Habits Questionnaire- 21(EHQ-21). [Orthorexia Nervosa: An investigation of the construct and psychometric properties of the Italian version of the Eating Habits Questionnaire-21 (EHQ-21)]. Psicoterap Cogn Comportam 23(3):291-316

32. Brytek-Matera A, Plasonja N, Décamps G (2020) Assessing orthorexia nervosa: validation of the Polish version of the Eating Habits Questionnaire in a general population sample. Nutrients 12(12):3820. https://doi.org/10.3390/nu12123820

33. Foa EB, Huppert JD, Leiberg S, Langner R, Kichic R, Hajcak G, Salkovskis PM (2002) The Obsessive-Compulsive Inventory: development and validation of a short version. Psychol Assess 14(4):485. https://doi.org/10.1037/1040-3590.14.4.485

34. Sica C, Ghisi M, Altoè G, Chiri LR, Franceschini S, Coradeschi D et al (2009) The Italian version of Obsessive Compulsive Inventory: Its psychometric properties on community and clinical samples. J Anxiety Disord 23:204-211. https://doi.org/10.1016/j. janxdis.2008.07.001

35. Jeśka M (2012) Narzędzia do pomiaru objawów zaburzenia obsesyjno-kompulsyjnego (zastosowanie, właściwości, wady i zalety) [Tools for measuring the symptoms of obsessivecompulsive disorder (application, properties, advantages and disadvantages)]. Neuropsychiatria Przegląd Klin 4(3):137-142

36. Mojsa-Kaja J, Golonka K, Gawłowska M (2016) Preliminary analyses of psychometric characteristics of the Polish version of the Obsessive-Compulsive Inventory-Revised (OCI-R) in a nonclinical sample. Int J Occup Med Environ Health 29(6):10111021. https://doi.org/10.13075/ijomeh.1896.00792

37. Frost RO, Marten P, Lahart C, Rosenblate R (1990) The dimensions of perfectionism. Cogn Ther Res 14(5):449-468. https://doi. org/10.1007/BF01172967

38. Strober J (1998) The Frost Multidimensional Perfectionism Scale Revisited: More perfect with four (instead of six) dimensions. Personal Individ Differ 24:481-491

39. Lombardo C (2008) Adattamento italiano della Multidimensional Perfectionism Scale (MPS). Psicoterap Cogn Comport 14(3):31-46

40. Piotrowski K, Bojanowska A (2019) Factor structure and psychometric properties of a Polish adaptation of the Frost
Multidimensional Perfectionism Scale. Curr Psychol. https://doi. org/10.1007/s12144-019-00198-w

41. Obsessive Compulsive Cognitions Working Group (2001) Development and initial validation of the obsessive beliefs questionnaire and the interpretation of intrusions inventory. Behav Res Ther 39:987-1006

42. Obsessive Compulsive Cognitions Working Group (2003) Psychometric validation of the obsessive belief questionnaire and the interpretation of intrusion inventory: Part 1. Behav Res Ther 41:863-878

43. Obsessive Compulsive Cognitions Working Group (2005) Psychometric validation of the obsessive belief questionnaire and interpretation of intrusion inventory. Part II. Behav Res Therapy 43:1527-1542

44. Novara C, Dorz S, Pastore M, Sica C, Sanavio E (2011) Presentazione della versione italiana dell'Obsessive Beliefs Questionnaire (parte II). Validità convergente e specificità dei costrutti in un campione clinico. Psicoterap Cogn Comport 17(2):157-172

45. Sajdakowska M, Królak M, Zychowicz W, Jeżewska-Zychowicz M (2018) Acceptance of food technologies, perceived values and consumers' expectations towards bread. A survey among Polish Sample. Sustainability 10:1281. https://doi.org/10.3390/su100 41281

46. Poyraz CA, Tüfekçioğlu EY, Özdemir A, Baş A, Kani AS, Erginöz E, Duran A (2015) Relationship between orthorexia and obsessive-compulsive symptoms in patients with generalised anxiety disorder, panic disorder and obsessive-compulsive disorder. Yeni Symposium 53(4):22-26. https://doi.org/10.5455/NYS.20151 221025259

47. Łucka I, Janikowska-Hołoweńko D, Domarecki P, PlenikowskaŚlusarz T, Domarecka M (2019) Orthorexia Nervosa: a separate clinical entity, a part of eating disorder spectrum or another manifestation of obsessive-compulsive disorder? Psychiatr Pol 53(2):371-382. https://doi.org/10.12740/pp/onlinefirst/85729

48. Zickgraf HF, Ellis JM, Essayli JH (2019) Disentangling Orthorexia Nervosa from healthy eating and other eating disorder symptoms: relationships with clinical impairment, comorbidity, and self-reported food choices. Appetite 134:40-49. https://doi.org/ 10.1016/j.appet.2018.12.006

49. Oberle CD, De Nadai AS, Madrid AL (2020) Orthorexia Nervosa Inventory (ONI): development and validation of a new measure of orthorexic symptomatology. Eat Weight Disord. https://doi.org/ 10.1007/s40519-020-00896-6

50. Ross PT, Bibler Zaidi NL (2019) Limited by our limitations. Perspect Med Educ 8:261-264. https://doi.org/10.1007/ s40037-019-00530-x

Publisher's Note Springer Nature remains neutral with regard to jurisdictional claims in published maps and institutional affiliations. 